\title{
Reformas na administração educacional: Uma análise comparada entre Brasil e Portugal
}

\author{
Elma Júlia Gonçalves de Carvalhoi \\ Universidade Estadual de Maringá, Brasil
}

\begin{abstract}
Resumo
Na última década vêm ocorrendo importantes alterações na organização e na administração da educação brasileira, entre as quais ganham relevância propostas de administração descentralizada, participativa e autônoma. Não se trata, todavia, de uma particularidade brasileira, pois essas propostas apresentam-se também nas reformas educativas empreendidas em outros países, correspondendo à emergência de um novo conceito de governação, o qual é produto do processo de (re)definição do papel do Estado e de (re)orientação de suas práticas, tendo por referência os novos modelos de gestão pública, que envolvem descentralização, reforço da autonomia e ampliação da participação social. Partindo dessas considerações, realizamos um estudo comparado das reformas ocorridas na administração do sistema educativo do Brasil e de Portugal com os objetivos de compreender as razões da relativa homogeneidade do novo modelo de gestão escolar e de identificar, ao mesmo tempo, as orientações comuns e as particularidades dos modos de apropriação de tal modelo nos dois países ${ }^{1}$.
\end{abstract}

Palavras-chave

Reconfiguração do papel do Estado; Nova gestão pública; Reformas educativas brasileira e portuguesa

\section{Introdução}

A partir da década de 1990, em vários países vêm ocorrendo alterações significativas no papel do Estado e nos processos de decisão 
política e de administração da educação. De modo geral, na agenda das reformas empreendidas pelos governos constam medidas de descentralização administrativa, ampliação da participação da comunidade local e reforço da autonomia dos sistemas e das escolas públicas. A consequente remodelação dos órgãos de gestão da escola implica, necessariamente, um aumento das competências (elaboração de projetos pedagógicos, criação de conselhos escolares) e das responsabilidades dos estabelecimentos de ensino (instauração de mecanismos de avaliação, controle e prestação de contas).

Modernização, melhoria da qualidade, maior eficiência, transparência, eficácia, flexibilidade e qualidade são os argumentos com que essas medidas vêm sendo justificadas. Contudo, existem evidências de que elas não se reduzem a uma simples modernização administrativa ou a uma dimensão meramente técnica, mas contêm motivações políticas, econômicas e sociais e fazem parte de um quadro de reinvenção do sistema de gestão pública cujos objetivos são: responder às exigências da globalização econômica e financeira, de forma a permitir maiores níveis de competitividade entre os países; reduzir a dívida pública; assegurar a legitimidade dos governos democráticos; e satisfazer às exigências do cidadão-consumidor. Faz parte do processo de reinvenção a introdução da lógica mercantil e gestionária na estrutura e na administração dos serviços públicos: submetendo bens e serviços às regras do mercado; incitando ao recurso de fundos privados; encorajando a competição entre os setores público e privado ou dentro do setor público; e promovendo sociedades de economias mistas, parcerias, etc.

Considerando a necessidade de compreender as razões da relativa homogeneidade do novo modelo de gestão escolar e de identificar, ao mesmo tempo, as orientações comuns e as particularidades de apropriação desse modelo nos diferentes países, realizamos um estudo comparado das reformas ocorridas na administração dos sistemas educativos do Brasil e de Portugal2 ${ }^{2}$. O presente texto tem como objetivo analisar comparativamente essas reformas, tendo como referência, especialmente, ordenamentos jurídicos e normativos, projetos e programas governamentais relacionados à administração da educação pública e comentários de autores portugueses e brasileiros a respeito. 


\section{As reformas educativas em perspectiva comparada}

Ao procedermos à comparação entre as reformas educativas ocorridas no Brasil e em Portugal nos anos de 1990, especialmente no que diz respeito à gestão da educação, o primeiro ponto a ser considerado é o contexto de crise e de importantes alterações políticas, sociais e econômicas, o que desafia os dois países a encontrarem alternativas para a administração pública. Observa-se em ambos a redefinição das funções do Estado e de sua lógica organizacional e administrativa, cujas estratégias envolvem principalmente o alargamento da participação da sociedade, a partilha de responsabilidades e a busca de novas fontes de financiamento, especialmente por meio de parcerias com o setor privado e com o terceiro setor, para o desenvolvimento das políticas sociais.

Por se considerar que as políticas educativas estão condicionadas por esse processo, pode-se afirmar que, em ambos os países, a descentralização, o reforço da autonomia das escolas e a participação surgem integrados à reforma do aparelho do Estado, cujas orientações têm por por base o modelo gerencial.

O modelo gerencial, ao influenciar a reforma administrativa, redirecionou as formas de intervenção do Estado e da gestão das políticas públicas, com implicações para a gestão educacional (Carvalho, 2009). Portanto, seguindo os novos paradigmas administrativos, as reformas da gestão educativa possuem algumas características-chave que simbolizam as novas propostas de gestão pública, a saber: ênfase na ação administrativa, privilegiando o cliente/consumidor - oferecendo-lhe opções; flexibilização nas organizações, em oposição à burocracia; introdução de políticas de autonomia e de descentralização administrativa e financeira; devolução de poderes para o nível local ou regional, embora combinada com (re)centralização dos poderes e novas formas de controle; encorajamento de uma cultura de iniciativa e participação mais ativas do cidadão; partilha ou redistribuição de responsabilidades - revisão das relações entre Estado, sociedade civil, empresas e poder local; adoção de parcerias entre o setor público e privado e entre as instituições do setor público; introdução de currículos e exames nacionais, objetivando criar normas-padrão e medidas de desempenho para aferir critérios de alocação de recursos, criar um referencial de competitividade, instituir mecanismos de prestação de contas e controle 
dos resultados no sistema educativo; introdução de mecanismos que incentivam a diversificação da oferta e a competição entre as escolas.

Assim, as mudanças relativas à gestão da educação em ambos os países estimulam a participação social, a autonomia e a descentralização administrativa, conforme novos conceitos e princípios organizacionais e administrativos das empresas privadas e das relações de mercado. Os critérios de adoção dessas medidas são definidos pelo valor econômico da educação (modernização, eficácia, eficiência, diversificação, qualidade e competitividade).

Pode-se constatar ainda que as transformações operadas na administração do sistema escolar brasileiro e na do português não se distinguem da orientação geral que preside às mudanças que vêm ocorrendo em outros países, sobretudo a partir dos anos de 1990. A tendência de convergência, cada vez maior, no nível macro da retórica e das reformas políticas, deve-se em grande parte aos efeitos dos processos de integração supranacional das economias e das políticas, designados por globalização ou mundialização, o que vem apontando para uma tendência crescente de constituição de uma agenda globalmente estruturada (Dale, 2001) para as reformas nos sistemas de educação dos diferentes países. As influências das organizações internacionais (OCDE, UNESCO, Banco Mundial, dentre outros) na formulação e legitimação das propostas, particularmente por meio de documentos produzidos (relatórios, boletins, recomedações, acordos, tratados, etc.), de conferências organizadas mundialmente e do auxílio técnico e financeiro, dinamizam a difusão dos modelos, dos padrões de organização, das normas e das opções de reforma e, ao mesmo tempo, transformam, uniformizam e homogeneízam as linhas de ação da política educativa, independentemente do contexto em que os países estejam situados.

A internacionalização dos fóruns de consulta e decisão política e a influência crescente das agências internacionais têm introduzido em diferentes países novas formas de regulação dos poderes públicos no sistema educacional, tendo em vista a redefinição do papel do "Estado educador" e a emergência de uma "regulação pelo mercado" (Barroso, 2003a). Além disso, observa-se que a educação emerge como campo de ação comunitário, seja no âmbito da União Europeia, seja no do Merscosul, o que tem favorecido a 
produção de normas de ação e referenciais ideológicos e políticos comuns. Contudo, segundo Barroso (2001),

apesar de existir um certo referencial comum no que respeita à adopção de determinadas orientações gerais (como sejam a descentralização, o reforço da autonomia das escolas, a participação local) e a adopção de medidas de caráter gestionário inspiradas na moderna gestão empresarial (ligadas à promoção da qualidade, da eficácia e da eficiência) (p. 249),

existe também a singularidade desse processo, no qual se verificam diferenças nacionais importantes (Barroso, 2003a). Isto porque as recomendações presentes nos documentos não são transpostas diretamente, pelo contrário, estão sujeitas a confrontos políticos, a resistências e a intrerpretações diferenciadas. Por isso, importa também ter em conta a especificidade do caso português e do brasileiro no campo das políticas educativas.

$\mathrm{Na}$ interpretação de Barroso (2001), quando as políticas de "autonomia" e "gestão centrada na escola" foram introduzidas em Portugal estavam longe de assumir "o objectivo expresso de criarem, de forma deliberada, um 'quase mercado de educação ${ }^{3}$ e de introduzir a lógica econômica que lhe está subjacente, na organização e funcionamento da escola pública (...)" (p. 248), a exemplo do que tem ocorrido no Reino Unido, nos EUA e na Nova Zelândia. Isso permite dizer que "(...) apesar de partirem de um diagnóstico semelhante sobre 'os males do sector público' e apresentarem algumas orientações comuns [adoção de medidas de caráter gestionário], elas diferem, contudo, quanto ao papel que o Estado deve manter e quanto à sua própria dimensão e natureza do serviço público" (Barroso, 2001, p. 205), variando substancialmente "(...) em função dos contextos políticos [antecedentes culturais e históricos da administração pública] e econômicos de cada país, bem como das características dos sistemas educativos em que se inserem (...)" (Barroso, 2003b, p. 95).

Um ponto de vista semelhante é manifestado por Almerindo Afonso (2000, p. 75). Ao analisar a questão da avaliação educacional, o autor afirma que "estas tendências [neoliberal e neoconservadora emergente no contexto internacional], todavia, parecem ser menos visíveis no caso de países (semi) periféricos como a Espanha e Portugal". Na interpretação do autor, em Portugal, no período entre 1985 e 1995, devido às "pressões contraditórias 
exercidas pelos diferentes grupos e classes sociais que participaram, directa ou indirectamente, na definição da política educativa" (Afonso, 1997), desenvolveu-se um "neoliberalismo educacional mitigado", isto é, "que simultaneamente parece apoiado sobre a expansão do Estado e a abertura senão favorecimento da iniciativa privada no domínio da educação" (Afonso, 1997, p. 152).

No Brasil, essa tendência, num primeiro momento, parece também não ser tão evidente. Porém, nos últimos anos temos observado inúmeras iniciativas que marcam a adoção de medidas administrativas de caráter gestionário, como também a penetração das empresas privadas no campo da educação pública, numa estratégia de quase-mercado, influenciando gestão, currículos das escolas e, em alguns casos, até mesmo a formação de professores, a exemplo dos programas coordenados pelo Instituto Ayrton Senna (IAS) ${ }^{4}$.

Ao comentar as novas estratégias de ampliação da presença do setor privado na oferta da educação pública, Adrião e Borghi (2008) destacam as parcerias. As autoras diferenciam três possíveis modalidades de parcerias: a compra pela rede pública de "sistemas de ensino" privados, o que diz respeito à aquisição de materiais didáticos (em geral apostilados); a subvenção de vagas em instituições privadas; e a "assessoria na gestão", o que revela novas estratégias de ampliação dos interesses privados na educação básica pública. Em geral essas parcerias têm sido firmadas pela rede pública municipal. Na interpretação de Adrião e Borghi (2008, p. 101), isso se justifica porque, com a descentralização da educação, cuja medida principal foi a municipalização do ensino, há a transferência de responsabilidades da gestão das etapas iniciais da educação básica para os municípios, o que tem favorecido "inúmeros arranjos localmente criados". A descentralização, ante a insuficiência de capacidade institucional, ou seja, diante das "dificuldades para a composição de um corpo técnico capaz de assumir a gestão local da educação", proporcionou condições não apenas para a "dependência pedagógica frente aos outros sistemas de ensino mais organizados", como também ampliou "a busca de apoio junto ao setor privado" (Adrião e Borghi, 2008, p. 105). Esses aspectos nos permitem afirmar que, no Brasil, a política de autonomia e descentralização administrativa, desprovida das condições adequadas, acabou por favorecer uma expansão surpreendente da atuação das redes privadas dentro do setor público. 
Embora, para os autores portugueses, em Portugal não tenha havido, num primeiro momento, a adoção das "regras do mercado" com a intenção explícita e sistemática de criação de um "mercado educativo", pode-se afirmar que nem por isso a "lógica do mercado" tenha deixado de existir (Barroso, 2001, p. 220). A versão economicista e gerencialista da gestão escolar, como alternativa ao centralismo e à burocracia, foi sendo gradualmente revelada, conforme Veiguinha (1998), "em certos aspectos, aparentemente secundários" (p. 69). Para esse autor, no Decreto-Lei $n^{\circ} 43 / 89$, que incide sobre o regime jurídico da autonomia da escola, começaram a ser registrados os primeiros indícios de tal orientação, ainda que de forma tímida, conforme pode ser observado nos artigos $20^{\circ}, 23^{\circ}$ e $24^{\circ}$.

Porém, o Decreto-Lei $n^{\circ}$ 172/91, que define a aplicação, em regime de experiência pedagógica, do novo modelo de gestão e administração, baseado nos princípios de democraticidade, participação e descentralização administrativa, com a transferência de poderes de decisão para o plano local inaugura uma nova fase da política educativa, tornando mais evidente a orientação gerencial na gestão das escolas portuguesas. Isso pode ser identificado na substituição do Conselho Diretivo, órgão coletivo de gestão, por um órgão unipessoal de gestão do estabelecimento de ensino, com concentração de poderes nas mãos do diretor-executivo. Esse aspecto aponta para o esvaziamento dos poderes e das competências efetivas do Conselho Pedagógico e para a "hipervalorização da racionalidade técnica", que, por sua vez, resulta numa "apologia do 'profissionalismo' do gestor". Isso pode ser interpretado como uma "recuperação neo-taylorista de princípios e técnicas de administração de tipo 'gerencialista' e aparece associado a um discurso que tende a valorizar os aspectos técnicos da gestão (esvaziando a sua conflitualidade, ideologia política e social)" (Barroso, 1995, p. 49).

Podemos considerar que essa tendência se manteve nos programas de governo e nas orientações legais mais recentes. Os programas eleitorais dos XV (2002-2004), XVI (2004-2005) e XVII (2005-2009) governos contêm aspectos comuns. Lima (2006), ao referir-se ao Programa do XVI Governo Constitucional, considera-o "genericamente idêntico uma vez que 'assenta na continuidade das políticas desenvolvidas pelo XV Governo' (Portugal, 2004), voltando a insistir na profissionalização da gestão e na criação da figura de director escolar, e ainda na simplificação da administração desconcentrada" 
(p. 34). Para o autor, o discurso político, ao afastar-se progressivamente do referencial democrático-participativo, "passará a ser preferencialmente marcado pela modernização do sistema e pela racionalização de recursos, pelo reordenamento da 'rede nacional de ofertas educativas' (não necessariamente pública, ao contrário do imperativo constitucional), pela competitividade e performatividade" (Lima, 2006, p. 35). O mesmo podemos dizer em relação às ordenações legais do Ministério da Educação, a exemplo do Decreto-Lei $n^{\circ}$ 208/2002, do Decreto-Lei $n^{\circ}$ 213/2006 e do Decreto-Lei $n^{\circ}$ $75 / 2008$, nas quais a orientação gerencialista se manifesta claramente. Ao almejar a modernização da administração educativa, as referidas leis pretendem atingir padrões mais elevados de eficiência, racionalização e estabilidade na utilização dos recursos humanos, materiais e financeiros, por meio de padrões de gestão desburocratizados e autônomos, da participação das comunidades educativas na gestão do sistema educativo, de maior especialização e profissionalização da gestão, e da avaliação e reponsabilização de todos os que compõem as comunidades educativas.

No Brasil, a existência de eleições diretas para a escolha de diretores (em alguns estados) e da gestão compartilhada, mediante a participação da comunidade escolar e local em Conselhos Escolares ou equivalentes (Lei 9394/96, Art. $14^{\circ}$, inciso II), aos quais compete, entre outras funções, a elaboração do projeto pedagógico da escola, afirma o princípio da gestão democrática. Apesar disso, a reforma educacional dos anos de 1990, ao centrar-se na gestão da unidade escolar como condição central para a melhoria da qualidade do ensino, entendida nos limites dos princípios da eficiência e da eficácia econômica, resultou no alargamento das responsabilidades e atribuições dos diretores e no fortalecimento do seu papel na gestão escolar. Pesquisas que analisam o impacto dos programas e projetos implantados nos últimos anos na gestão da escola destacam a tendência de ênfase na liderança do diretor, bem como o fato de ele ser colocado no centro da estrutura do poder, tornando-se o principal responsável por executar, controlar e avaliar as ações desenvolvidas na escola (Krawczyk \& Vieira, 2008). Ao mesmo tempo, tem havido, por parte dos poderes públicos, uma preocupação com a atuação do profissional da educação no campo da gestão, o que leva o próprio Ministério da Educação - MEC, isoladamente ou em parceria com as secretarias de educação, universidades, 
associações da área ou entidades que as representam, a exemplo do Conselho Nacional de Secretários da Educação (Consed), da União Nacional dos Dirigentes Municipais de Educação (Undime) e do Conselho de Reitores das Universidades Brasileiras (Crub), a implementar programas de capacitação de dirigentes, numa perspectiva de formação técnico-profissional da gestão como parte de uma política de valorização crescente do papel do gestor escolar e de fortalecimento do seu poder, numa perspectiva gerencialista.

Um exemplo recente é o Plano de Desenvolvimento da Escola (PDEEscola), principal projeto do Fundescola 5 no âmbito escolar. Conforme estudos de Fonseca (2009), o programa, que provém de um acordo financeiro entre Banco Mundial (Bird) e MEC, a princípio foi concebido para atender às regiões mais pobres do Brasil (norte, nordeste e centro-oeste), denominadas de Zonas de Atendimento Prioritário - ZAP, sendo, após o lançamento do Plano de Desenvolvimento da Educação - PDE (2007) ${ }^{6}$, expandido para outras regiões do país. Segundo a autora, embora a missão do PDE-Escola seja a de "elevar o conhecimento e o compromisso dos diretores, professores e outros funcionários com os resultados educacionais; estimular a gestão participativa e o acompanhamento dos pais nas atividades em geral e na aprendizagem dos filhos", a sua execução, no âmbito escolar, "visa promover a autonomia e o fortalecimento da gestão escolar por meio de uma metodologia de planejamento estratégico centrada na racionalização, na eficácia e na eficiência do desempenho escolar". Para isso, é importante que os administradores sejam qualificados. Nesse sentido, "os documentos oficiais afirmam que, por meio do PDE, a gestão educacional incorpora um sentido peculiar, treinando e dotando os agentes escolares de 'atributos gerenciais' e de 'ferramentas de gestão' (...)" (Brasil/Mec/Fundescola, 2002, cit. por Fonseca, 2009, pp. 273-274).

Em Portugal, em virtude das oposições e resistências ao Decreto-Lei $n^{\circ}$ 172/91, impôs-se ao Ministério da Educação a necessidade de elaboração de um novo diploma legal sobre gestão da escola, em obediência à Lei de Bases do Sistema Educativo (LBSE) ${ }^{7}$ - Lei $n^{\circ} 46 / 86$, consagrando um modelo que buscasse garantir a democratização dos órgãos e que reduzisse os riscos de subordinação da escola à lógica do tipo empresarial. O Decreto-Lei n ${ }^{\circ} 115-$ $\mathrm{A} / 98$, que regula a autonomia, administração e gestão dos estabelecimentos 
públicos da educação pré-escolar e dos ensinos básico e secundário, segundo Veiguinha (1998, p. 92), representou essa possibilidade, por não contemplar a distinção entre os órgãos de direção e os de gestão. Conforme o Decreto, ao Conselho Pedagógico seria atribuída a responsabilidade pela elaboração do projeto da escola, do plano anual e do regulamento interno da escola, ao passo que ao diretor ou ao conselho executivo, enquanto órgão de gestão, caberia a responsabilidade pelas questões de caráter organizativo e administrativo. $O$ diretor assume, assim, mais um papel de administradoreducador do que de "chefe-executivo" ou "gestor profissional", cuja autoridade formal se faz em decorrência do projeto educativo da escola.

No debate que antecedeu a aprovação dessas medidas, a lógica de mercado e suas propostas se fizeram presentes. Contudo, na interpretação de Barroso (2001, p. 253), elas não foram majoritárias e tiveram de se confrontar com as lógicas de outras posições - a estatal, a de mercado, a corporativa e a comunitária -, que disputaram a formulação da política educativa. O resultado foi "uma amálgama de retóricas e medidas contraditórias que procuram traduzir um aparente compromisso entre essas lógicas" (Barroso, 2001, p. 254), ou, conforme expressão de Afonso (1998, p. 227), uma política educativa híbrida ${ }^{8}$, como é o caso das escolas profissionais, caracterizadas por um "projecto que se origina no Estado, mas que pretende proclamar-se como uma aposta na iniciativa local: um projecto de escola-mercado contemplado no âmbito de uma política educativa liberalizante onde se defende a gestão privada dos recursos públicos" (Stoer, cit. por Afonso, 1998, p. 221). Desse modo, segundo os autores, Portugal também se diferencia de países como o Reino Unido, os EUA e a Nova Zelândia, pois adota uma perspectiva menos radical de liberalização e privatização (introdução da lógica do mercado no campo da educação).

Nesse aspecto, pode-se considerar que há uma semelhança com o Brasil, onde políticas neoliberais têm enfrentado forte oposição e têm-se confrontado com outros interesses. Porém, apesar das pressões contraditórias, os autores brasileiros, diferentemente dos portugueses, não fazem referência à presença de um neoliberalismo mitigado (Afonso, 1998) como parte do processo de elaboração e implantação das políticas educacionais nos anos de 1990, mas se referem a uma clara hegemonia neoliberal. Para eles, as lógicas economicista e gerencialista têm sido 
introduzidas por meio de medidas provisórias, propostas de emendas constitucionais, decretos e vetos por meio dos quais o Executivo centraliza as decisões, num processo em que, ao mesmo tempo em que se acatam as orientações dos organismos multilaterais, ignoram-se os debates e pressões advindos da sociedade civil organizada.

No caso brasileiro, essa lógica não é explícita na legislação, ela só aparece de maneira mais nítida nos programas e projetos, a exemplo do Acorda Brasil (1995), em que a comunidade é conclamada a colaborar com a educação; do Programa Dinheiro Direto na Escola - PDDE (1995), em que recursos são repassados diretamente para a escola, atribuindo-se às unidades executoras ou Associação de Pais e Mestres (APMs) o papel não só de gerenciar os recursos recebidos, mas também o de gerar receitas adicionais; e, mais recentemente, do Plano de Desenvolvimento da Educação - PDE (2007). O PDE integra um conjunto de programas cujo objetivo é dar organicidade ao sistema nacional de educação, superando a tradicional visão fragmentada das políticas educacionais e a falta de articulação das ações entre os entes federados (União, Distrito Federal, estados e municípios), a fim de promover a melhoria da educação básica. Conforme palavras do então Ministro da Educação Fernando Haddad, o regime de colaboração, ou seja, o compartilhamento de "competências políticas, técnicas e financeiras para a execução de programas de manutenção e desenvolvimento da educação", associado à responsabilização e à mobilização social são indicados como dimensões indispensáveis do Plano (Haddad, 2008, p. 8).

Para operacionalizar esse Plano, o Governo Federal baixou, em 24 de abril de 2007, o Decreto $n^{\circ} 6.094$, que dispõe sobre a implementação do Plano de Metas Compromisso Todos pela Educação $^{9}$, pela União Federal, em regime de colaboração com Municípios, Distrito Federal e Estados, e a participação das famílias e da comunidade, mediante programas e ações de assistência técnica e financeira, visando a mobilização social pela melhoria da qualidade da educação básica, ao qual os municípios e estados devem se vincular, por meio de um termo de adesão voluntária, para poder receber assistência técnica ou financeira do MEC. O Decreto estabelece 28 diretrizes e um conjunto de metas a ser atingido por cada escola, cada município e cada estado. De acordo com o documento, cabe aos diferentes sistemas de ensino, dentre outras atribuições: promover a gestão participada; elaborar plano de 
educação e instalar Conselho de Educação; acompanhar e avaliar, com a participação da comunidade e do Conselho de Educação, as políticas na área da educação; fomentar e apoiar os Conselhos Escolares, envolvendo as famílias dos educandos na atribuição de zelar pela manutenção da escola e pelo monitoramento das ações e consecução das metas do compromisso; firmar parcerias externas à comunidade escolar, visando a melhoria da infraestrutura da escola ou a promoção de projetos socioculturais e ações educativas. Para a verificação do cumprimento, pelo ente federado, das metas fixadas no termo de adesão ao Compromisso foi criado o Índice de Desenvolvimento da Educação Básica (Ideb) ${ }^{10}$.

Em Portugal, conforme os autores portugueses, a princípio a lógica da regulação mercantil esteve presente na responsabilização e no controle das escolas pelos resultados; entretanto, de modo mais atenuado. Para Natércio Afonso (2003), "o reforço da avaliação externa institucional e do controlo da escola pela via da pressão da procura parental pode ser detectado também em França e em Portugal, porém em termos mais discretos e com menor impacto no cotidiano escolar" (p. 70). Ou ainda, embora as políticas governamentais procurassem promover o envolvimento dos pais, das autarquias e de outros atores locais, particularmente empresariais, "os resultados pouco ultrapassaram um efeito meramente retórico" (Afonso, 2003, p. 70).

No Brasil a proposta de autonomia avançou de maneira menos tímida, ao mesmo tempo em que revelou maior predisposição para assumir a concepção gerencialista, especialmente a partir do governo Fernando Henrique Cardoso (1995-2003), quando claramente ocorreu uma "subordinação ativa e consentida à lógica do mercado" (Frigotto \& Ciavatta, 2003). Por exemplo, por um lado, o Estado passou a subsidiar as escolas de acordo com o número de alunos, a promover a competição por meio da divulgação de resultados e prêmios de gestão escolar, a permitir maior flexibilidade de organização escolar (definição de calendário, reclassificação dos alunos, definição do currículo local, como forma de tornar a escola mais adaptada às necessidades dos clientes), e a fixar metas de desempenho; por outro, embora os vetores do modelo gerencial não apareçam de forma explícita na fundamentação e nos modelos de referência de algumas medidas políticas, em particular as relacionadas com autonomia da gestão da 
educação, foram introduzidos currículos e exames nacionais como forma de controle e responsabilização das escolas pelos resultados educativos. Essa tendência se manteve no governo Lula (2003-2011) de modo mais sistemático, especialmente com o Programa de Desenvolvimento da Educação - PDE (2007).

Em Portugal, num primeiro momento, conforme Almerindo Afonso (1995), ao referir-se ao modelo de direção e gestão no Decreto-Lei no ${ }^{0}$ 172/91, os vetores do 'novo management' "encontram-se, evidentemente, no nível mais geral da definição das políticas, mas, em termos de orientações concretas para a gestão das escolas, não se traduziram de forma tão transparente como à primeira vista pode parecer" (p. 79). Todavia, para o autor, não parecia ser "(...) possível falar de uma valorização, mais do que retórica, dos estilos de gestão do sector privado no domínio da educação pública não superior" (Afonso, 1995, p. 79).

Apesar disso, o próprio autor não deixava de reconhecer que o sistema de ensino português estava, naquele momento, suscetível a "introduzir a lógica de mercado e a competição nas escolas de ensino básico e secundário" (Afonso, 1995, p. 80). Isso acaba por tornar-se mais evidente a partir de 2003, especialmente com a mudança de governo, quando chegou ao poder uma coligação de centro-direita. Barroso (2003b), na época, declarou que, ainda que não tenham sido adotadas medidas de fundo, "parece existir uma estratégia de redução da intervenção do Estado na regulação e prestação do serviço educativo, com a promoção de um mercado da educação e a adopção de critérios e modalidades de gestão empresarial" (p. 74). Contudo, para o autor, até aquele momento essa situação "ainda não estava suficientemente clarificada" (Barroso, 2003b, p. 74).

Entretanto, em relação ao contexto atual não se pode dizer o mesmo; pelo contrário. Ao comentar o curso das reformas em Portugal, Lima (2009) aponta que "os discursos governamentais, a legislação ordinária e uma boa parte das agendas de política educativa, mesmo no interior das escolas, deslocaram-se para a gestão eficaz e a flexibilidade, a competitividade e a produtividade, a contratualização e a mercadorização" (p. 241). As perspectivas gerencialistas e tecnocráticas foram sendo mais bem evidenciadas especialmente a partir do Decreto-Lei $n^{\circ}$ 208/2002 e do DecretoLei $n^{\circ} 75 / 2008$, que aprova o "Regime de autonomia, administração e gestão 
dos estabelecimentos públicos da educação pré-escolar e dos ensinos básico e secundário". Esse Decreto estabelece como objetivos estratégicos: "o reforço da participação da família e da comunidade na direcção estratégica dos estabelecimentos de ensino"; o favorecimento da "constituição de lideranças fortes"; o reforço da autonomia da escola articulada com autoavaliação e avaliação externa a ser realizada pelo Ministério da Educação.

Um outro aspecto que merece destaque refere-se ao fato de que, em Portugal, embora consagrada em diversos normativos legais, a autonomia ainda não se efetivou nos domínios da escola. Isso tem levado à conclusão de que a autonomia não se constrói por decreto. Ou que, "na maior parte dos casos, estes decretos (e em especial os seus preâmbulos) não passam de retórica oficial que é sistematicamente desmentida pelas normas regulamentadoras, diga-se de passagem, de um grau excessivo de pormenorização e detalhe (em particular as que definem os meios e afectam recursos), bem como pelas práticas dos diversos actores que, na administração central ou regional, ocupam lugares de decisão estratégicos em relação ao funcionamento das escolas" (Barroso, 2001, p. 256).

Com efeito, em Portugal os ordenamentos jurídicos têm contribuído, de forma pouco expressiva, para a construção de um modelo de administração, direção e gestão escolar descentralizado e autônomo. Em outros termos, decreta-se a autonomia de forma discursiva, sem proceder à transferência de certos poderes de decisão para as escolas. Desse modo, a autonomia das escolas, como valor democrático, continua circunscrita à categoria de "'"discurso retórico" em "programas dos governos e preâmbulos dos diplomas legais" (Lima, 2009, p. 235). Disso resulta, para os autores portugueses, que a evolução nesse terreno parece depender mais da mobilização e do posicionamento das escolas e dos atores escolares.

Embora a política educativa resulte do jogo de forças dos atores envolvidos, nos últimos anos o que se tem verificado é uma orientação voltada à profissionalização da gestão, à generalização e centralidade da figura do director escolar (liderança unipessoal em detrimento dos órgãos colegiados), a estruturas mais concentradas em termos de departamentos centrais, ao reforço da desconcentração, à modernização do sistema e à racionalização de recursos. A referida orientação encontra-se de forma bastante evidente no 
Decreto-Lei $n^{\circ}$ 208/2002, que, com o objetivo de promover uma reforma estrutural no âmbito do sistema educativo, trata de procedimentos relativos à administração educativa. Ainda, segundo Lima (2006), "também a participação democrática de professores, alunos, pais e pessoal não docente nos órgãos de direcção e gestão das escolas (Artigo $77^{\circ}$ da Constituição) seria transferida para 'serviços especializados' e 'órgãos consultivos' (Artigo $44^{\circ}, n^{\circ} 5$ do Projecto Governamental)" (p. 37).

Mais recentemente, com o Decreto-Lei $n^{\circ} 75 / 2008$, os órgãos de administração da escola passam a ser: o Conselho Geral, o Director, o Conselho Pedagógico e o Conselho Administrativo. O Conselho Geral, cujo mandato tem a duração de quatro anos, substitui a Assembleia da Escola, instituída pelo Decreto-Lei $n^{\circ} 115-\mathrm{A} / 98$. Desse modo, num contexto marcado progressivamente pela adoção da orientação gerencialista no campo da gestão pública, o atual Decreto, em relação à gestão da escola, celebra a transição da colegialidade para a unipessoalidade, conferindo protagonismo às "lideranças individuais, fortes e eficazes", ou a "um executivo que concentra mais poder e competências" (Lima, 2009, p. 247).

Embora pareça haver, no Brasil, uma visão mais otimista em relação a essa questão, especialmente pelo fato de a legislação (Lei 9394/96) apontar para a criação de órgãos colegiados de gestão nas várias esferas do governo e nos estabelecimentos de ensino, convergindo para a gestão democrática e descentralizada, essa continua ainda a ser, muito mais, "peça de retórica". Observa-se, assim, que em relação a esse aspecto parece não haver diferenças entre os dois países. As pesquisas realizadas não têm demonstrado a existência de alterações substantivas nas estruturas administrativas das escolas. Conforme Krawczyk e Vieira (2008), "os estudos sobre as políticas educacionais orientadas por uma perspectiva democrática demonstram que estas não conseguiram os resultados esperados" (p. 66).

Um outro aspecto bastante discutido em Portugal relaciona-se ao fato de "a reforma educativa ter sido um processo centralizado e incapaz de romper com a lógica tradicional, fortemente normativa e prescritiva, a que as escolas e os actores educativos periféricos têm sido tradicionalmente sujeitos" (Afonso, 1998, p. 214). O centralismo administrativo e burocrático também marcou a organização e o funcionamento das instituições brasileiras ao longo do século $\mathrm{XX}$, apesar dos movimentos em prol da descentralização 
administrativa. Como consequência, esse modelo está profundamente arraigado na cultura brasileira, o que, de certo modo, dificulta o desenvolvimento de uma nova racionalidade que envolva autonomia, flexibilidade e participação.

No Brasil, tal como em Portugal, apesar da ênfase retórica dada à descentralização, participação e autonomia, no sentido de partilhar poderes e competências, verifica-se a possibilidade de um movimento de desconcentração, mediante a delegação de poderes e transferência de responsabilidades de gestão para os níveis locais e regionais e, ao mesmo tempo, de concentração do poder de decisão e (re)concentração de autoridade no âmbito do governo central, nomeadamente do Ministério da Educação. Assim, contemplando a lógica gerencialista, as reformas promovidas, ao mesmo tempo em que centralizam a tomada de decisões ou definição das políticas, descentralizam a sua execução em âmbito local (municípios e escolas).

Ao comentar a situação portuguesa, Lima (2006) descreve que o preâmbulo, comum, dos decretos regulamentares publicados em 2004 dispõe que as direções regionais, enquanto instâncias administrativas intermediárias, "embora fazendo parte integrante da administração central de tipo desconcentrado" devem garantir, por parte das escolas e dos agrupamentos, "a fidedignidade da execução das políticas educativas elaboradas com o apoio dos serviços centrais" (p. 36). A referida orientação também está presente no Decreto-Lei $n^{\circ} 208 / 2002$, que, ao reconhecer que os municípios são parceiros essenciais no desenvolvimento da educação, consagra a devolução de novas atribuições às autarquias locais. No entanto, apresenta uma estrutura administrativa mais concentrada, ao extinguir todos os institutos públicos dotados de autonomia e ao criar novos órgãos centrais de administração da educação (Lima, 2006). Esse Decreto foi revogado pelo Decreto-Lei $n^{\circ}$ 213/2006; entretanto, manteve-se a mesma estrutura. Mais recentemente, o Decreto-Lei $n^{\circ}$ 75/2008 reafirma essa tendência de execução das políticas no âmbito da escola.

De nossa perspectiva, a legislação brasileira não é tão explícita quanto a portuguesa. Entretanto, consideramos que essa tendência se evidencia de forma sutil nos projetos e programas governamentais, nos quais se observa que "ao mesmo tempo em que as políticas educativas descentralizam os 
sistemas de ensino e estabelecem bases para a autonomia da gestão das instituições escolares, o Estado regulamenta, avalia e monitora as unidades escolares e mantém centralizadas as decisões relevantes" (Carvalho, 2009, p. 1157).

Observamos que, do mesmo modo que em Portugal, no Brasil o reforço dos poderes da administração central tem-se manisfestado por meio de "processos de desconcentração, da imposição de outras lógicas de reordenamento da rede de escolas, entre outras formas de controle sobre as escolas" (Lima, 2006, p. 6). No caso brasileiro isso tem ocorrido principalmente por meio de programas que vinculavam premiações ou o recebimento de recursos extras do MEC ao desempenho alcançado ou ao cumprimento de metas pelos estabelecimentos públicos, como é o caso do PDE e de programas como o PDE-Escola.

Em Portugal as formas de participação, na prática, têm-se revelado como um instrumento de transferência de responsabilidades. Esse aspecto já era observado nas Atas do Seminário do Fórum Português de Administração Educacional, realizado em 1995, cujos debates sobre a descentralização educativa e sobre o poder local nas práticas educativas revelam que o município continua a ser considerado um mero coparticipante dos custos da educação, sem qualquer direito, mesmo que limitado, de interferir nas decisões fundamentais em matéria educativa. Conforme Fernandes (1996), na perspectiva das normas vigentes, a descentralização

no que ao nível autárquico se refere, não tem passado de metáfora semântica através da qual se tem procurado disfarçar uma transferência de ônus financeiros no domínio das construções escolares e dos transportes, de acção social escolar, da educação infantil e especial e na formação profissional (...) sem poderes sequer de gestão dos edifícios de que são proprietários.

Essas declarações tornam evidente que o sentido da descentralização e o papel que cabe às autarquias nas orientações normativas (Decreto-lei 77/84 e LBSE de 86) resumem-se à execução de políticas. Elas não têm o poder de definir as próprias políticas regionais: a administração central mantém a centralização das funções de concepção, planejamento e decisão, predominando uma concepção do "poder autárquico como mero contribuinte forçado de recursos financeiros do sistema público de educação" (Fernandes, 1996). 
Não nos parece que a realidade brasileira difira da realidade portuguesa também nesse aspecto. A municipalização no Brasil se traduziu numa transferência de encargos e gastos do governo central para os municípios. Nesse sentido, observa-se que, no decorrer dos anos 1990, foi produzida uma legislação fortemente indutora da municipalização, a exemplo da Emenda Constitucional 14/96, que criou o Fundo de Manutenção e Desenvolvimento do Ensino Fundamental e de Valorização dos Profissionais da Educação - FUNDEF11, e da LDB - Lei 9694/96. A LDB, ao distribuir e organizar as responsabilidades das três esferas administrativas (União, estados e municípios) define, em seu Art. 11, que compete ao município, como ente federativo autônomo, "I - organizar, manter e desenvolver os órgãos e instituições oficiais dos seus sistemas de ensino, integrando-os às políticas e planos educacionais da União e dos Estados" e que "os Municípios poderão optar, ainda, por se integrar ao sistema estadual de ensino ou compor com ele um sistema único de educação básica", enquanto ao Fundef coube transferir recursos diretamente aos sistemas de ensino, com base no número de alunos e fomentar a passagem de escolas, especialmente de séries iniciais do ensino fundamental, que anteriormente estavam sob jurisdição estadual, para a esfera municipal. No entanto, paralelamente a essa distribuição de responsabilidades e atribuições, configurou-se o "fortalecimento do papel do Ministério da Educação como planificador e controlador da política educacional" (Oliveira, 2002, p. 70).

A partir dessas afirmações, é também possível concluir que é comum entre os dois países "a concepção de governança do Estado, o qual deve assumir um papel ativo na definição e controle das políticas e não na sua execução/operacionalização" (Oliveira, 2002, p. 70). Em outros termos, o Estado, ao mesmo tempo em que define prioridades e metas, monitora os resultados conforme as orientações do novo modelo gerencial. Portanto, as propostas de descentralização e autonomia atuais têm mais a ver com a transferência de encargos de uma esfera para a outra, especialmente em relação às funções executivas, do que propriamente com a ampliação do poder de decisão, mantendo-se a tendência centralizadora, que institui, segundo Lima (2009), uma "administração de tipo centralizadodesconcentrado" (p. 235). 


\section{Considerações finais}

A reflexão sobre as reformas educativas, numa perspectiva comparada, permite verificar que certos discursos e medidas coincidem, existindo uma tendência de se promoverem políticas de descentralização, participação e autonomia das escolas e de novas formas de controle, segundo o modelo da nova gestão pública. Não obstante, as configurações particulares de que se reveste a gestão local da escola e o tipo de autonomia reconhecido variam muito de país para país e não atingem, de igual modo, os diversos setores de decisão sobre o funcionamento do sistema educativo. Além disso, quando postas em prática, não produzem os efeitos verificados em outros contextos, segundo o ponto de vista de diversos autores (Afonso, 1998; Barroso, 2001; Afonso, 2003).

Entretanto, é impossível não se considerar que a proposta de autonomia e de descentralização é parte do movimento histórico no qual o papel do Estado está sendo redefinido em todos os países. Esse movimento internacional, independentemente das peculiaridades das políticas e da correlação de forças políticas locais, segue uma mesma lógica, cujas características são a retração do Estado central na prestação direta do serviço da educação e uma alteração nos modos de regulação, por parte do poder público, no sistema escolar, o que consiste em substituir as estratégias de regulação, centradas na produção normativa, pelo controle dos resultados, com o reforço da participação da comunidade e a criação de múltiplos dispositivos de avaliação e de controles indiretos.

Também se pode chegar à conclusão de que, em decorrência das mudanças significativas na concepção do serviço público, no conceito de responsabilização do Estado e no seu modo de atuação e regulação, bem como das pressões contraditórias da sociedade (nacional, supranacional), a ação pública, no decorrer da década de 1990, foi sendo estruturada no sentido de combinações, complementaridades ou articulações entre as diversas lógicas de ação. Trata-se de uma construção sob novos arranjos e fórmulas institucionais em que o Estado não é o único protagonista na estratégia de legitimação das políticas e de garantias de governabilidade e na determinação do teor e do sentido da proposta de autonomia da gestão escolar. 
Verifica-se, ainda, que o processo de reformas educativas especialmente o relativo à autonomia de gestão das escolas públicas, tanto em Portugal quanto no Brasil, é conduzido com

muitas ambiguidades, inconstâncias, indefinições e contradições, seja nos discursos seja nos planos e projetos governamentais e nas orientações normativas. A análise dos documentos e das reflexões teóricas sobre as reformas revela que o processo tem sido marcado pela indefinição tanto quanto às competências nos níveis de administração (escolas, municípios), quanto à atribuição de responsabilidades, em decorrência da redução do papel do Estado e da abertura do campo educacional para a iniciativa privada, ou seu favorecimento. O processo tem sido marcado também por contradições que podem ser expressas pelos seguintes termos em oposição: centralização/descentralização; local/global; participação social/intervenção do Estado; flexibilização/controle do Estado; público/privado.

A análise comparada permite verificar ainda que, do mesmo modo que no Brasil, em Portugal, nos anos de 1970/1980, a defesa da autonomia/descentralização estava vinculada a uma perspectiva de liberdade, bem como de participação e (re)democratização da sociedade, após um período de ditadura. Porém, do mesmo modo, em ambos os países o atual discurso sobre descentralização e autonomia incorporou grande parte dos termos dos movimentos contestatórios, despojando-os de seu sentido político democrático-participativo da década de 1980 e (res)semantizando-os segundo a inspiração gerencial e produtivista. A respeito desse aspecto, que vem sendo denunciado por vários autores, julga-se necessário chamar a atenção. Trata-se, assim, de se ter em conta que a análise crítica das políticas públicas, visando desocultar os princípios ideológicos da retórica, não pode desconsiderar que se torna necessário pôr em evidência, de um lado, os aspectos gerencialistas presentes na organização e na administração escolar e, de outro, o debate que se lhe opõe, cuja expectativa é a criação de alternativas para a gestão da educação pública.

Portanto, em relação à autonomia da escola pública existem provavelmente diversas possibilidades em termos de futuro, cuja realidade política será sempre decorrente do confronto de vários interesses. Por isso, embora as atuais políticas apontem para uma tendência gerencialista da gestão escolar, isso não significa necessariamente que ela se concretize 
inteiramente na prática. Dito de outro modo, o destino do projeto de descentralização, participação e autonomia da escola irá depender muito mais do "jogo de forças" dos atores sociais, e quem sabe poderá se submeter a outras lógicas. Segue um campo aberto de disputas.

\section{Notas}

1 Versão preliminar deste texto foi apresentada oralmente no III Encontro Internacional de Estudos Comparados em Educação, Buenos Aires - Argentina, Junho de 2011.

2 O estudo foi inicialmente desenvolvido com o apoio da Coordenação de Aperfeiçoamento de Pessoal de Nível Superior (Capes), resultado do estágio de doutorado no exterior - Programa de Doutorado Sanduíche, realizado na Universidade do Minho, Braga (2004), sob orientação do Prof. Licínio Lima, e posteriormente se tornou objeto de investigação do Projeto de Pesquisa intitulado "Políticas de autonomia da gestão escolar: Uma análise comparada entre Brasil e Portugal", desenvolvido no Departamento de Teoria e Prática da Educação da Universidade Estadual de Maringá - Brasil, concluído em 2010.

3 Roger Dale (2000, p. 139), ao referir-se à educação em termos de quase-mercado, afirma que "o que está em questão são novas formas e combinações de financiamento, fornecimento e regulação da educação (...). O Estado pode retirarse completamente quer do financiamento quer do fornecimento da educação, mantendo, contudo, a autoridade reguladora que somente ele pode exercer e, com ela, o controle último do sistema", de modo a redefinir as relações tradicionais entre os setores público e privado.

4 Organização não-governamental sem fins lucrativos, fundada em 1994. "O IES exerce grande infuência na educação pública do país: atualmente, são atendidas 7.896.146 crianças e jovens, envolvendo 410.770 educadores, 1.360 municípios atingidos em 25 estados" (Peroni, 2008, p. 119).

5 O Fundescola (Fundo de Fortalecimento da Escola) é um programa do Fundo Nacional de Desenvolvimento da Educação, executado em parceria com a Secretaria de Educação Básica do Ministério da Educação (SEB/MEC) e desenvolvido com as secretarias estaduais e municipais de educação das regiões Norte, Nordeste e Centro-Oeste. Tem por objetivo promover um conjunto de ações para a melhoria da qualidade das escolas do ensino fundamental, ampliando a permanência das crianças nas escolas públicas, assim como a escolaridade nas regiões Norte, Nordeste e Centro-Oeste. Sua missão é promover, em regime de parceria e responsabilidade social, a eficácia, a eficiência e a equidade no ensino fundamental público dessas regiões por meio da oferta de serviços, produtos e assistência técnico-financeira inovadores e de qualidade, que focalizam o ensinoaprendizagem e as práticas gerenciais das escolas e secretarias de educação (Brasil/MEC, 2011). O Fundescola foi concebido como um programa abarcando vários projetos ou ações, dentre eles o PDE-Escola. 
50 Elma Júlia Gonçalves de Carvalho

6 O PDE aparece como um grande guarda-chuva, que abriga praticamente todos os programas do MEC, abrangendo todos os níveis e modalidades de ensino, além de medidas de apoio e de infraestrutura.

7 A Lei $n^{\circ} 46 / 86$ adota como princípios organizativos "contribuir para desenvolver o espírito e a prática democráticos, através da adopção de estruturas e processos participativos na definição da política educativa, na administração e gestão do sistema escolar e na experiência quotidiana, em que se integram todos os intervenientes no processo educativo, em especial os alunos, os docentes e as famílias" (Artigo $\left.3^{\circ}, b\right)$.

8 O efeito do hibridismo, segundo Barroso (2003), "(...) resulta da sobreposição ou mestiçagem de diferentes lógicas, discursos e práticas na definição e acção das políticas, o que reforça o seu carácter ambíguo e compósito".

9 Cabe destacar que, por meio desse Decreto, o Governo Federal assumiu plenamente a agenda do "Compromisso Todos pela Educação", lançado em 2006. O movimento se apresentou como uma iniciativa da sociedade civil, mas, de fato, se constituiu como uma proposta de um grupo de empresários. A ação revela o protagonismo que o empresariado vem assumindo na formulação da política educacional brasileira.

10 O Ideb é um indicador que será calculado e divulgado periodicamente pelo Instituto Nacional de Estudos e Pesquisas Educacionais (Inep), com base nos dados sobre aprovação escolar, obtidos no Censo Escolar, e médias de desempenho de avaliação nas avaliações do Inep: o Saeb, para as unidades da federação e para o país, e a prova Brasil, para os municípios. A partir do Ideb, cujo cálculo é realizado por escola, por rede e para o próprio País, são fixadas metas de desenvolvimento educacional, promovendo conexões entre avaliação, financiamento e gestão.

11 O Fundo de Manutenção e Desenvolvimento do Ensino Fundamental e de Valorização do Magistério (Fundef) é um fundo de natureza contábil, composto de $60 \%$ dos recursos públicos vinculados à educação dos estados e municípios, os quais são recolhidos pela União e repassados de volta, para as contas do Fundef, na proporção da oferta de matrículas do ensino fundamental. O Fundo instituiu também o valor mínimo por aluno-ano e definiu que a União deve completar os recursos do Fundo sempre que cada Estado, Distrito Federal e Município não alcancem o valor mínimo fixado por aluno nacionalmente. Nesse caso, reserva à União uma função redistributiva e supletiva que funcionaria como uma ação redutora das disparidades regionais. O Fundef foi substituído pelo Fundo de Manutenção e Desenvolvimento da Educação Básica e de Valorização dos Profissionais da Educação (Fundeb - 2007), estendendo-se as matrículas da educação infantil ao ensino médio.

\section{Referências}

Adrião, T., \& Borghi, R. (2008). Parcerias entre prefeituras e esfera privada: Estratégias privatizantes para a oferta da educação pública em São Paulo. In T. Adrião \& V. Peroni (Org.), Público e privado na educação: Novos elementos para o debate (pp. 99-110). São Paulo: Xamã. 
Afonso, A. J. (1995). O novo modelo de gestão das escolas e a conexão tardia à ideologia neoliberal. Revista Portuguesa de Educação, 8(1), 73-86.

Afonso, A. J. (1997). Para a configuração do Estado-Providência na educação em Portugal (1985-1995). Educação, Sociedade \& Culturas, 7, 131-156.

Afonso, A. J. (1998). Políticas educativas e avaliação educacional. Para uma análise sociológica da reforma educativa em Portugal (1985-1995) (Tese de doutorado). Universidade do Minho, Braga.

Afonso, A. J. (2000). Avaliação educacional: Regulação e emancipação (2a ed.). São Paulo: Cortez Editora.

Afonso, N. (2003). A regulação da educação na Europa: Do Estado educador ao controlo social da Escola Pública. In J. Barroso (Org.), A escola pública: Regulação, desregulação e privatização (pp. 48-78). Porto: Asa.

Barroso, J. (1995). Para uma abordagem teórica da reforma da administração: A distinção entre "direcção" e "gestão". Revista Portuguesa de Educação, 8(1), 33-56.

Barroso, J. (2001). Relatório da disciplina "Teoria das Organizações e da Administração Educacional". Faculdade de Psicologia e Ciências da Educação da Universidade de Lisboa, Lisboa.

Barroso, J. (2003a). A "escolha da escola" como processo de regulação: Integração e seleção social? In J. Barroso (Org.), Escola pública - Regulação, desregulação e privatização (pp. 79-109). Porto: Asa.

Barroso, J. (2003b). Organização e regulação dos ensinos básico e secundário, em Portugal: Sentidos de uma evolução. Educação \& Sociedade, 82(24), 63-92.

Brasil/ Ministério da Educação (2011). Fundescola: O programa. Disponível em: www.fundescola.org.br (acesso em 7 de outubro de 2011).

Carvalho, E. J. (2009). Reestruturação produtiva, reforma administrativa do Estado e gestão da educação. Educação \& Sociedade, 10(109), 1139-1166.

Dale, R. (2000). O marketing do mercado educacional e a polarização da educação. In P. Gentille (Org.). Pedagogia da exclusão: Crítica ao neoliberalismo em educação (6 ${ }^{\mathrm{a}}$ ed.) (pp. 137-168). Rio de Janeiro: Vozes.

Dale, R. (2001). Globalização e educação: Demonstrando a existência de uma "cultura educacional mundial comum" ou localizando uma "agenda globalmente estruturada para a educação"? Educação, Sociedade \& Culturas, 16, 133-169.

Fernandes, A. S. (1996). A gestão democrática das escolas. Notas sobre a experiência das escolas secundárias após a Revolução de 25 de Abril. O Ensino, 11/12/13, 77-83.

Fonseca, M. (2009). É possível articular o projeto pedagógico e o plano de desenvolvimento da escola? Reflexões sobre a reforma do Estado e a gestão da escola. In E. B. Ferreira \& D. A. Oliveira, Crise da escola e políticas educativas (pp. 271-286). Belo Horizonte: Autêntica Editora.

Frigotto, G., \& Ciavatta, M. (2003). Educação Básica no Brasil na década de 1990: Subordinação ativa e consentida à lógica do mercado. Educação \& Sociedade, 34(32), 99-130. 
Haddad, F. (2008). O plano de desenvolvimento da educação: Razões, princípios e programas. Brasília: Instituto Nacional de Estudos e Pesquisas Educacionais Anísio Teixeira.

Krawczyk, N. R., \& Vieira, V. L. (2008). A reforma educacional na América Latina nos anos de 1990: Uma perspectiva histórico-sociológica. São Paulo: Xamã.

Lima, L. C. (2006). Administração da educação e autonomia das escolas. In L. C. Lima, J. A. Pacheco, M. Esteves \& R. Canário (Orgs.), A educação em Portugal (19862006): Alguns contributos de investigação (pp. 5-54). Lisboa: Sociedade Portuguesa de Ciências da Educação. Disponível em: http://espacoseducativos.files.wordpress.com/2007/05/a-educacao-emportugal-1986-2006-alguns-contributos-de-investigacao.pdf (acesso em 3 de março de 2011).

Lima, L. C. (2009). A democratização do governo das escolas públicas em Portugal. Sociologia, 19, 227-253.

Oliveira, C. (2002). Gestão da educação: União, estado/distrito federal, municípios e escolas. In L. M. Machado \& N. S. C. Ferreira (Orgs.), Política de gestão da educação: Dois olhares (pp. 69-82). Rio de Janeiro: DP\&A Editora.

Peroni, V. (2008). A relação público/privado e a gestão da educação em tempos de redefinição do papel do Estado. In T. Adrião \& V. Peroni, Público e privado na educação: Novos elementos para o debate (pp. 111-127). São Paulo: Xamã.

Veiguinha, J. J. (1998). Autonomia da escola e projecto educativo de escola: Que perspectivas. Finisterra, 26, 63-94.

\section{Legislação}

Decreto $n^{\circ}$ 6.094, de 24 de abril de 2007. Diário da União. Brasília

Decreto-Lei n 115-A/98, de 4 de Maio. Diário da República. Lisboa.

Decreto-Lei n 172/91, de 10 de Maio. Diário da República. Lisboa.

Decreto-Lei n 208/2002, de 17 de Outubro. Diário da República. Lisboa.

Decreto-Lei $n^{\circ}$ 213/2006, de 27 de Outubro. Diário da República. Lisboa.

Decreto-Lei n 43/89, de 3 de Fevereiro. Diário da República. Lisboa.

Decreto-Lei n ${ }^{\circ}$ 75/2008, de 22 de Abril. Diário da República. Lisboa.

Decreto-Lei $n^{\circ} 77 / 84$, de 8 de Março. Diário da República. Lisboa.

Lei 46/86, de 14 de outubro de 1986. Lei de Bases do Sistema Educativo. Diário da República. Lisboa.

Lei $n^{\circ}$ 9394, de 20 de dezembro de 1996. Estabelece a Lei de Diretrizes e Bases da Educação Nacional. Diário Oficial da União, 22 dez. 1996, seção I (p. 21.870). Brasília, DF. 
REFORMS IN EDUCATIONAL MANAGEMENT: A COMPARATIVE ANALYSIS BETWEEN BRAZIL AND PORTUGAL

\begin{abstract}
Important changes within the organization and administration of Brazilian education have occurred during the last decade. Suggestions for decentralized, participatory and independent educational management have been on the increase. These issues are, in fact, not a Brazilian particularity since they are on the agenda of the educational reforms in other countries. In fact, the phenomenon is more extensive and coincides with the emergence of a new governing concept which, in its turn, is part and parcel of the process involving the (re)definition of the role of the State and of the (re)orientation of its praxes. Since the new models of public management involves decentralization, reinforcement of autonomy and widening of social participation, these three factors are the categories on which current comparative study reforms occurred in the administration of the education system in Brazil and Portugal. Data of these studies are employed in current essay to discuss the reasons of the relative homogenization of the new model of school administration and, at the same time, identify common guidelines and particularities in the appropriation of the model in both countries.
\end{abstract}

\title{
Keywords
}

Reconfiguration of the role of the State; New public management; Brazilian and Portuguese education reforms 
RÉFORMES DANS L'ADMINISTRATION ÉDUCATIONNELLE: UNE ANALYSE COMPARÉE BRÉSIL-PORTUGAL

\section{Résumé}

Pendant la dernière décade, d'importants changements dans l'organisation et dans l'administration de l'éducation au Brésil sont en train d'avoir lieu, parmi lesquels sont mis en évidence des propositions envisageant une administration décentralisée, participative et autonome. Pourtant, ceci n'est pas une particularité brésilienne: de telles propositions apparaissent aussi dans les réformes éducatives entreprises en d'autres pays, ce qui montre que ce fait est beaucoup plus ample, correspondant à l'émergence d'un nouveau concept de gestion, qui, à son tour, fait partie du processus de (re)définition du rôle de l'État et de (re)orientation de ses pratiques. Étant donné que ces nouveaux modèles de gestion publique comprennent la décentralisation, le renforcement de l'autonomie et de la participation sociale, sont celles-ci les catégories que nous prenons en tant que base pour réaliser une étude comparée des réformes survenues dans l'administration du système d'éducation au Brésil et au Portugal. En utilisant les données de cette étudelà, l'objectif de ce texte est de discuter les raisons de la relative homogénéité du nouveau modèle de gestion scolaire et d'identifier, au même temps, les orientations communes et les particularités des modes d'appropriation de ce modèle dans les deux pays.

Mots-clé

Reconfiguration du rôle de l'État; Nouvelle gestion publique; Réformes éducatives brésilienne et portugaise 